Available online on 15.07.2020 at http://jddtonline.info
Open Access to Pharmaceutical and Medical Research
unrestricted non-commercial use, provided the original work is properly cited

Open 1 Access

Research Article

\title{
Development of Capecitabine Floating Tablet Dosage Forms for Treating Stomach Cancer
}

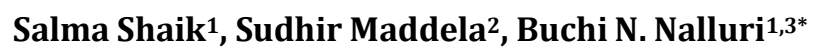 \\ 1Department of Pharmaceutics and Biotechnology, KVSR Siddhartha College of Pharmaceutical Sciences, Vijayawada-520010, AP, INDIA \\ ${ }^{2}$ Research Scholar, Department of Pharmacy, Krishna University, Machilipatnam, AP, INDIA \\ ${ }^{3}$ Siddhartha Pharma Innovation and Incubation Center at KVSR Siddhartha college of Pharmaceutical Sciences, Vijayawada-520010, AP, INDIA
}

\begin{abstract}
Objective: In the present research work, oral gastro retentive dosage forms (GRDFs) of capecitabine (CPC) were formulated using floating concept.

Methods: GRDFs were formulated using hydroxypropyl methyl cellulose (HPMC K4M and K15M) as drug release retardant, sodium bicarbonate $\left(\mathrm{NaHCO}_{3}\right)$ and calcium carbonate $\left(\mathrm{CaCO}_{3}\right)$ as gas generating agents, and micro crystalline cellulose (MCC), dicalcium phosphate (DCP), spray dried lactose (SDL), and pre gelatinized starch (PGS) as fillers. The tablets were prepared by direct compression method and evaluated for various parameters. The GRDFs were also characterized by Fourier-transform infrared spectroscopy (FTIR), and differential scanning calorimetry (DSC).
\end{abstract}

Results and Discussion: All the formulations were subjected for pre and post compression parameters, shows all the data within the limits. The lag times of GRDFs has decreased significantly for formulations containing calcium carbonate when compared to sodium bicarbonate as gas generating agent. In vitro drug release studies indicate that higher polymer concentration delayed the CPC release, and the sustaining effect was in the order K4M > K15M > LVCR 100. Addition of MCC, DCP, SDL, and PGS as fillers further affected the lag time and in turn the CPC release rates.

Conclusion: The formulation (F9) containing 10\%w/w HPMC K4M as the release retardant, microcrystalline cellulose as filler and 20\%w/w $\mathrm{CaCO}_{3}$ as gas generating agent fulfilled regulatory requirements in terms of percent drug release at the end of $24 \mathrm{~h}$.

Keywords: Capecitabine, Gastro retentive floating tablets, floating drug delivery systems, FTIR, DSC.

Article Info: Received 09 April 2020; Review Completed 22 June 2020; Accepted 02 July 2020; Available online 15 July 2020

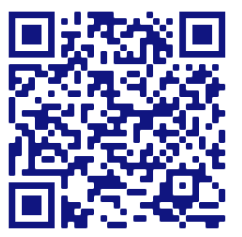

Cite this article as:

Shaik S, Maddela S, Nalluri BN, Development of Capecitabine Floating Tablet Dosage Forms for Treating Stomach Cancer, Journal of Drug Delivery and Therapeutics. 2020; 10(3-s):199-205 http://dx.doi.org/10.22270/jddt.v10i3-s.4171

*Address for Correspondence:

Vijayawada-520010, AP, INDIA

\section{INTRODUCTION}

Stomach cancer or gastric cancer refers to cancer arising from any part of the stomach. Gastric cancer is fourth most common worldwide cancer, with an estimated of 934,000 new cases per year and the second most common cause of worldwide cancer deaths with an estimated 700,000 deaths annually ${ }^{1}$. Geographically, the incidence and prevalence rates are higher in Asia, Eastern Europe and South America than in Western Europe and North America ${ }^{2}$.

5-Fluorouracil (5-FU) is one of the most widely used anticancer agents in the chemotherapy of solid tumors including gastric cancer. Treatment with 5-FU infusion requires either frequent hospitalizations or the use of central venous access device, harboring potential complications.
Prodrugs of 5-FU like Tegafur and Doxifluridine have been developed to improve selectivity toward tumors than 5-FU. However, the oral administration of these drugs requires higher doses than intravenous injection due to first pass effects and moreover, adverse effects such as diarrhoea have been reported following the administration of Tegafur or Doxifluridine $^{3}, 4$. These factors, together with the known patient preference for oral chemotherapy generated the need for an oral anticancer agent such as capecitabine (CPC) a tumor activating oral prodrug of 5-FU which improves safety and efficacy without or with fewer side effects.

CPC (N4-pentyloxycarbonyl-5'-deoxy-5-fluorocytidine) is an oral fluoropyrimidine carbamate prodrug and has wider and more potent spectrum of antitumor activity than other 
fluoropyrimidines administered at their maximum tolerated doses when tested against the xenograft models of human breast, cervical and bladder as well as gastric cancers ${ }^{5,6}$. The efficacy of CPC has been shown to be additive with Irinotecan and supradditive with either Paclitaxel or Docetaxel and further higher antitumor activity with Trastuzumab or Bevacizumab than CPC alone-6.

Human pharmacokinetic studies have also shown that after oral administration, CPC is rapidly and almost completely absorbed through the gastrointestinal wall, thus avoiding direct intestinal exposure to $5-\mathrm{FU}^{9}$. $\mathrm{CPC}$ is considered to be bio activated into 5-FU by three enzymes.After oral administration, CPC is first metabolized by carboxyl esterase in the liver to $5^{\prime}$-deoxy-5-fluoroctidune ( $5^{\prime}$-DFCR), which is then converted to 5'-deoxy-5-fluorouridine (5'-DFUR) by cytidine deaminase in the liver and tumor tissue. Finally, 5'-
DFUR is converted to 5-FU by thymidine phosphorylase, which is found at much higher levels in gastric cancer tissue than in normal tissue, enabling preferential activation of the active drug, 5'-FU, at tumor site ${ }^{10}$. CPC and its metabolites, 5'DFCR \& 5'-DFUR, are not cytotoxic themselves, but become effective after conversion to $5^{\prime}$-FU.

However, CPC also undergoes non enzymatic hydrolysis in aqueous buffers and may coverts to $5^{\prime}$ - DFCR (Fig. 1) ${ }^{11}$. CPC is well absorbed from the gastrointestinal tract (GIT); its plasma half-life is about 45-60min and these properties make CPC as an ideal candidate for developing a GRDF for treating stomach/gastric cancers.Considering the above context of principles, the present investigation was aimed at developing a once-daily oral proto-type gastro retentive dosage forms of CPC based on the floating technology.<smiles>CCCCCOC(=O)Nc1nc(=O)n(C2OC(C)C(O)C2O)cc1F</smiles>

Capecitabine<smiles>CC1OC(n2cc(F)c(N)nc2=O)C(O)C1O</smiles>

5'-DFCR

Figure 1: Acidic hydrolysis of CPC to 5'- DFCR

\section{MATERIALS AND METHODS}

\section{Materials}

Capecitabine was obtained as a gift sample from Divi's Laboratories, Hyderabad, India. HPMC K4M, HPMC K15M and HPMC LVCR 100, partially pre gelatinized starch were obtained from Colorcon Ltd, India. Sodium bicarbonate and calcium carbonate were purchased from CDH Pvt Ltd, India. Micro crystalline cellulose was obtained from FMC biopolymer, USA and spray dried lactose with maize starch was obtained from Roquette Pharma, France. Dicalcium phosphate, talc and magnesium stearate were purchased from Loba Chemie, India. All other reagents of analytical grade and all the solvents in HPLC are of HPLC grade.

\section{HPLC Method}

A reverse phase HPLC method was used for the analysis of CPC and 5'-DFCR in different samples. Chromatographic separation was performed on a Shimadzu Prominence HPLC system equipped with LC 10 AT VP binary pumps, SPD-10A VP UV Detector. LC solution software was used to collect and process the data. Mobile phase consisting of Acetonitrile: Ammonium acetate (50:50\% v/v) was used and the mobile phase was filtered through nylon disc filter of $0.45 \mu \mathrm{m}$ (Millipore) and sonicated for $3 \mathrm{~min}$ in ultrasonic bath before use. The flow rate was $1 \mathrm{~mL} / \mathrm{min}$ and the injection volume was $20 \mu \mathrm{L}$. UV detection was performed at $268 \mathrm{~nm}$ and the separation was achieved at ambient temperature. For quantitative analytical purpose, eluents were monitored at $268 \mathrm{~nm}$ and an Apollo $\mathrm{C}_{18}$ column $(150 \mathrm{~mm} \times 4.6 \mathrm{~mm}, 5.0 \mu)$ was used and separation was carried out at ambient temperature with an injection volume of $20 \mu \mathrm{L}$. The retention times for CPC and 5'-DFCR were $1.7 \mathrm{~min}$ and $2.5 \mathrm{~min}$ respectively.

\section{Stability Studies of CPC in 0.1N HCl}

$10 \mathrm{mg}$ of CPC was dissolved in $10 \mathrm{~mL}$ of volumetric flask containing $5 \mathrm{~mL}$ of HPLC grade water and volume was made up to with the same, to yield $1 \mathrm{mg} / \mathrm{mL}$ stock solution. The stock solution was subsequently diluted with $0.1 \mathrm{~N} \mathrm{HCl}$ to get $20 \mu \mathrm{g} / \mathrm{mL}$; resulting solution was stored in an incubator at $37^{\circ} \mathrm{C}$. The samples were collected at different time intervals $2,4,6,8,12,24 \& 48 \mathrm{hrs}$. The samples were filtered and analyzed using the above developed HPLC method.

\section{Drug- Excipient Compatibility Studies:}

Fourier Transmittance Infrared Spectroscopy (FTIR) Studies:

The FT-IR spectra of CPC and optimized formulation i.e. F9 (containing $\mathrm{CPC}, \mathrm{HPMC} \mathrm{K} 4 \mathrm{M}, \mathrm{CaCO}_{3}, \mathrm{MCC}$, Magnesium stearate and Talc) were measured using ATR-FTIR spectrophotometer (Bruker, Germany). ATR spectra were measured over the wave number range of $4000-500 \mathrm{~cm}^{-1}$ at a resolution of $1.0 \mathrm{~cm}^{-1}$. The powder sample is simply placed onto the ATR crystal and the sample spectrum is collected.

\section{Differential Scanning Calorimetry (DSC)Studies:}

Thermal analysis of CPC alone and CPC with selected excipients like $\mathrm{NaHCO}_{3}, \mathrm{PGS}$, and optimized formulation i.e. F9 (containing $\mathrm{CPC}, \mathrm{HPMC} \mathrm{K} 4 \mathrm{M}, \mathrm{CaCO}_{3}, \mathrm{MCC}$, Magnesium stearate and Talc) was performed using DSC instrument (DSC 200 F3 Maia, USA). The sample was sealed in a crimped aluminium pan by application of the minimum possible pressure and heated at a rate of $10^{\circ} \mathrm{C} / \mathrm{min}$ from $30-200^{\circ} \mathrm{C}$ under nitrogen atmosphere. 


\section{Preparation of CPC Floating Tablets:}

CPC floating tablets were prepared by direct compression method (as per formulae given in Table I). All the ingredients were passed through sieve \# 80 before mixing. Initially drug and polymers were mixed thoroughly and then required quantities of fillers were added and finally the blend was mixed with talc and mixed thoroughly for $5 \mathrm{~min}$ in a poly bag and then required amount of magnesium stearate was added and mixed for another $5 \mathrm{~min}$. Powder blends (for 50 tablets each) of all the above formulations were compressed on single punch tablet press (Cadmach, India) using $10 \mathrm{~mm}$ punches (round shape) to a hardness of $4-6$ $\mathrm{kg} / \mathrm{cm}^{2}$.

Table I: Composition of CPC floating tablets

\begin{tabular}{|c|c|c|c|c|c|c|c|c|c|c|c|c|}
\hline $\begin{array}{l}\text { Ingredients } \\
\text { (m/tab) }\end{array}$ & F1 & F2 & F3 & F4 & F5 & F6 & F7 & F8 & F9 & F10 & F11 & F12 \\
\hline CPC & 150 & 150 & 150 & 150 & 150 & 150 & 150 & 150 & 150 & 150 & 150 & 150 \\
\hline HPMC K4M & 40 & 60 & 80 & 100 & - & - & 80 & 60 & 40 & 40 & 40 & 40 \\
\hline HPMC K15M & - & - & - & - & 80 & - & - & - & - & - & - & - \\
\hline LVCR100 & - & - & - & - & - & 80 & - & - & - & - & - & - \\
\hline MCC & 126 & 106 & 86 & 66 & 86 & 86 & 86 & 106 & 126 & - & - & - \\
\hline PGS & - & - & - & - & - & - & - & - & - & 126 & - & - \\
\hline SDL & - & - & - & - & - & - & - & - & - & - & 126 & - \\
\hline DCP & - & - & - & - & - & - & - & - & - & - & - & 126 \\
\hline $\mathrm{NaHCO}_{3}$ & 80 & 80 & 80 & 80 & 80 & 80 & - & - & - & - & - & - \\
\hline $\mathrm{CaCO}_{3}$ & - & - & - & - & - & - & 80 & 80 & 80 & 80 & 80 & 80 \\
\hline Magnesium Stearate & 2 & 2 & 2 & 2 & 2 & 2 & 2 & 2 & 2 & 2 & 2 & 2 \\
\hline Talc & 2 & 2 & 2 & 2 & 2 & 2 & 2 & 2 & 2 & 2 & 2 & 2 \\
\hline Total weight & 400 & 400 & 400 & 400 & 400 & 400 & 400 & 400 & 400 & 400 & 400 & 400 \\
\hline
\end{tabular}

\section{Evaluation Parameters for Powder Blends and} Compressed CPC Tablets:

Pre compression parameters of the prepared powder blend of all the formulations were determined by determining the bulk density, tapped density, compressibility index, hausner's ratio and angle of repose ${ }^{12,13}$. Compressed floating tablets were characterized for weight variation $(n=20)$, hardness $(n=6)$ was measured with a Monsanto tester Campbell Electronics (India), friability $(n=20)$, with a Roche type friabilator. The drug content in each formulation was determined by triturating 5 tablets in a mortar and powder equivalent to the $20 \mathrm{mg}$ was added in $20 \mathrm{~mL}$ of HPLC grade water, followed by sonication for $15 \mathrm{~min}$. The solution was then filtered, suitably diluted with acetonitrile: ammonium acetate $(75: 25 \% \mathrm{v} / \mathrm{v})$ and analyzed by HPLC method.

\section{In Vitro Drug Release Studies:}

The tablets were subjected to in vitro drug release studies using USP-Type II (paddle) dissolution rate test apparatus (LABINDIA, DS 8000) at a temperature of $37 \pm 0.5^{\circ} \mathrm{C}$ and $50 \mathrm{rpm} .900 \mathrm{~mL}$ of $0.1 \mathrm{~N} \mathrm{HCl}$ was used as the dissolution medium. $5 \mathrm{~mL}$ aliquots of the samples were withdrawn at specific time intervals over a period of $24 \mathrm{hrs}$ and filtered using a $0.45 \mu \mathrm{m}$ nylon disc filters and replaced with $5 \mathrm{~mL}$ of fresh dissolution medium. The filtered samples were suitably diluted if necessary and analyzed for CPC \& 5'-DFCR by the HPLC method as described above. The dissolution experiments were conducted in triplicate.

\section{Drug release kinetics:}

The rate and mechanism of cumulative amount of CPC \& 5'DFCR released from the prepared floating tablets were analyzed by fitting the dissolution data into the Zero-order, First-order, Higuchi and Korsmeyer-Peppas equations ${ }^{15-17 .}$

\section{RESULTS AND DISCUSSION}

\section{Stability Studies:}

The hydrolysis of CPC to 5'-DFCR was carried out by storing stock solution of $\mathrm{CPC}$ in $0.1 \mathrm{~N} \mathrm{HCl}$ at $37^{\circ} \mathrm{C}$ over a period of time. Samples were removed at different time points and subjected to HPLC analysis. From the stability data it is clearly evident that CPC was rapidly hydrolyzed to 5'-DFCR under non enzymatic acidic conditions with a half-life of 0.73hrs (Fig.2) ${ }^{11}$.

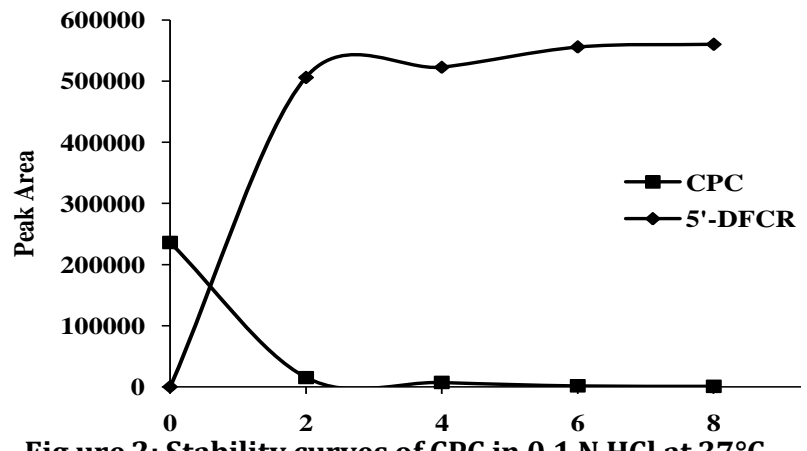

Fig ure 2: Stability curves of CPC in $0.1 \mathrm{~N} \mathrm{HCl}$ at $37^{\circ} \mathrm{C}$. 


\section{Drug - Excipient Compatibility Studies:}

\section{FTIR Studies:}

FTIR studies were carried with a view to evaluate the in situ CPC and excipients compatibility. FTIR spectra of CPC and F9 were shown in Fig.3(A) and 3(B) respectively. Pure CPC showed characteristic IR absorption bands at $1038 \mathrm{~cm}$ $1,1115 \mathrm{~cm}^{-1}, 1337 \mathrm{~cm}^{-1}, 1645 \mathrm{~cm}^{-1}, 1707 \mathrm{~cm}^{-1}, 3516 \mathrm{~cm}^{-1}$,
$3178 \mathrm{~cm}^{-1}$ indicating the presence of $\mathrm{C}-\mathrm{N}$ group, $\mathrm{C}-\mathrm{O}-\mathrm{C}$ group in aromatic ring, $\mathrm{C}-\mathrm{F}$ group, $\mathrm{C}=\mathrm{N}$ group, $\mathrm{C}=\mathrm{O}$ group, bending of $\mathrm{N}-\mathrm{H}$ group, and $-\mathrm{OH}$ groups respectively in $\mathrm{CPC}$ structure. These significant bands of CPC were also present in the FTIR spectra of CPC-excipient physical mixtures. These results indicate that compatibility of CPC with the selected excipients in formulation development studies.
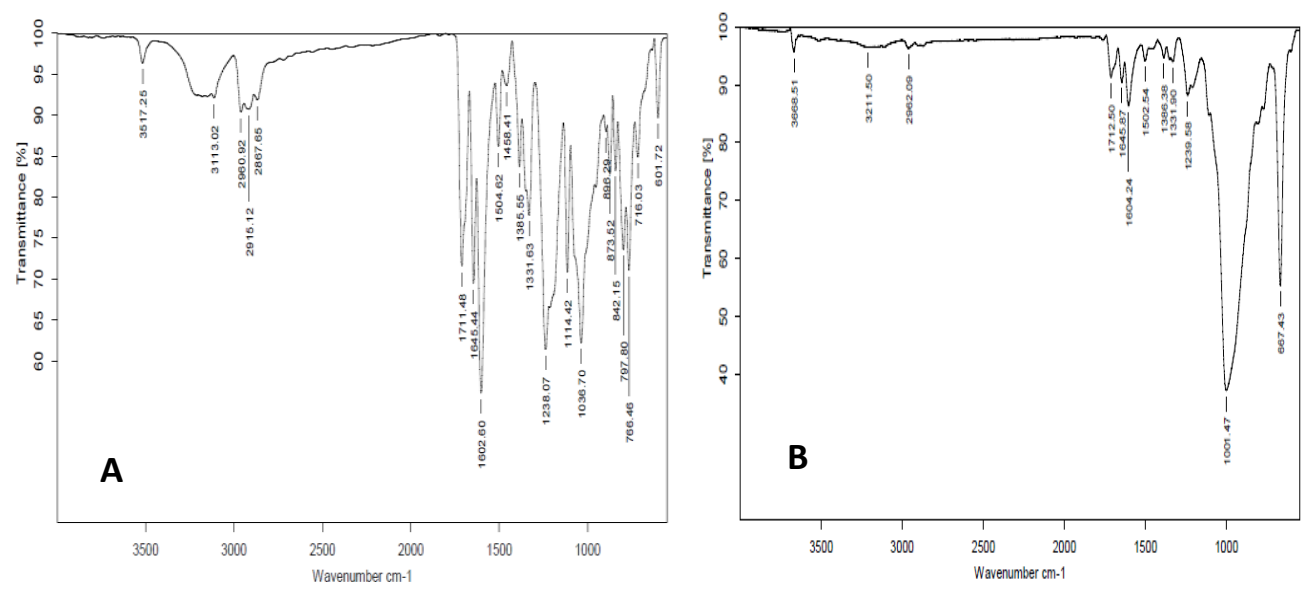

Figure 3 : FTIR spectra of CPC (A) and F9 (B)

\section{DSC Studies:}

DSC studies were also carried out to further investigate the chemical compatibility of CPC with the selected excipients. DSC thermograms of the CPC alone and CPC with the selected excipients and optimized formulation (F9) were shown in Fig.4.The CPC showed a sharp endothermic peak at around $121^{\circ} \mathrm{C}$ corresponding to its melting point ${ }^{17}$.The sharp endothermic at $121^{\circ} \mathrm{C}$ corresponds to the melting point of CPC and was retained in all the thermograms of $1: 1 \mathrm{w} / \mathrm{w}$ physical mixtures of the CPC and selected excipients like $\mathrm{NaHCO}_{3}, \mathrm{PGS}$ and also in optimized formulation (F9). These results indicated that the $\mathrm{CPC}$ was compatible with all the selected excipients in the formulations and there was no chemical interaction.

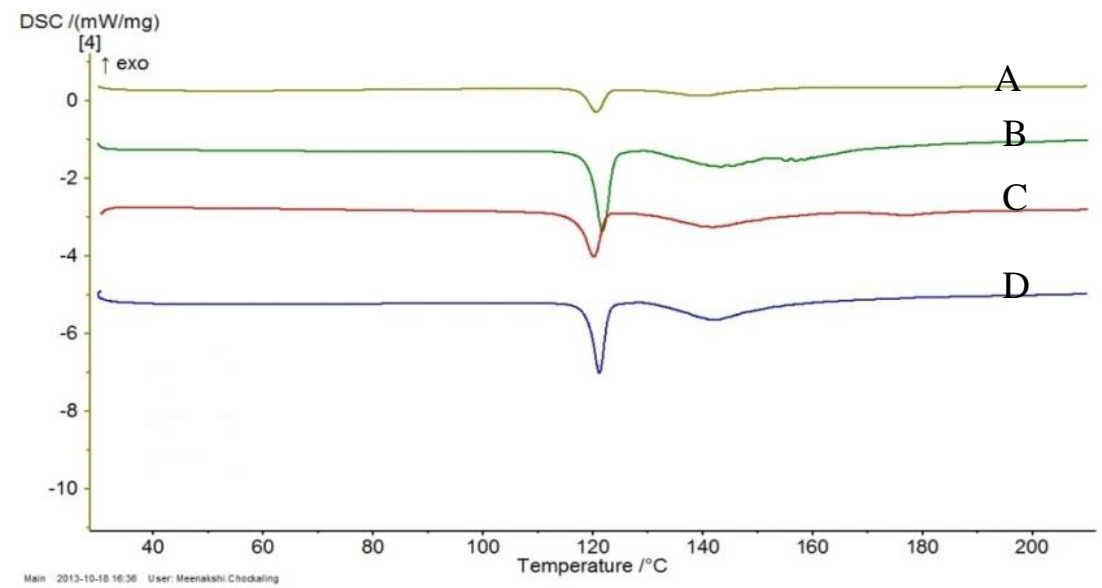

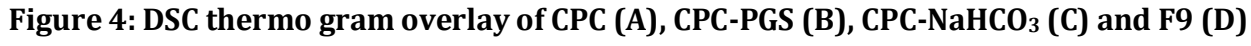

\section{Pre and Post Compression Parameters:}

The results of various pre compression parameters (Carr's index, Hausner's ratio, and angle of repose) for powder blends of all formulations were found to be within the acceptable range and are suitable for compression to tablets using direct compression method. The compressed tablets fulfilled the official compendial requirements with regarding drug content, uniformity of weight, hardness and friability, except with F11 and F12 where reproducibility of hardness was not achieved.

\section{In Vitro Drug Release Studies:}

In the present investigation, totally 12 different formulations were formulated using swellable hydrophilic polymers like HPMC of different grades (HPMC K4M and HPMC K15M) as release retardant materials and $\mathrm{NaHCO}_{3}$ and $\mathrm{CaCO}_{3}$ as gas generating agents and fillers like PGS, maize starch with SDL and DCP. Cumulative percent of CPC released i.e. CPC \& 5'DFCR together with different formulations at various time intervals were calculated. The floating lag times for all the formulations were determined and that for formulations F1- 
F5 containing $\mathrm{NaHCO}_{3}$ as gas generating agent were in the range of $10-38 \mathrm{sec}$, while that were with $\mathrm{CaCO}_{3}$ was in the range of 300-3600 sec.

\section{Effect of Release Retardant Concentration, Viscosity and} Gas Generating Agent on CPC Release:

Initial formulation studies were carried out to look in to the release retarding effect of HPMC K4M at concentration levels of $10,15,20,25 \% \mathrm{w} / \mathrm{w}$ in $\mathrm{F} 1-\mathrm{F} 4$ respectively using 20\%w/w $\mathrm{NaHCO}_{3}$ as gas generating agent and MCC as filler. F1, F2, F3, F4 gave an initial burst release of $23.74 \pm 0.397 \%, 23.30 \pm$ $0.59,20.15 \pm 0.08 \%$ and $17.73 \pm 0.73 \%$ respectively at the end of $1 \mathrm{hr}$ and a complete CPC release was attained at the end of $16 \mathrm{hrs}$ and $20 \mathrm{hrs}$ for $\mathrm{F} 1$ and $\mathrm{F} 2$ respectively, whereas $94.4 \pm 2.19 \%$ and $91.28 \pm 0.09 \%$ for F3 and F4 respectively at the end of $24 \mathrm{hrs}$. In all the cases the tablets were intact and a gel layer was retained up to $24 \mathrm{hrs}$. The comparative dissolution profiles of F1-F4 were shown in Fig.5 (A). From the results it can be concluded that the HPMC K4M at concentration levels of $20 \% \mathrm{w} / \mathrm{w}$ and $25 \% \mathrm{w} / \mathrm{w}$ was able to retard the release of $\mathrm{CPC}$, a water soluble drug, from floating tablets over a period of $24 \mathrm{hrs}$ successfully and moreover, there is no statistical significant difference between the cumulative amount of CPC released, the HPMC 20\% w/w concentration was selected further to investigate the effect of HPMC viscosity on release of CPC from floating tablets.

Further studies were carried out by developing F5 with $20 \% \mathrm{w} / \mathrm{w}$ HPMC K15M as release retardant, gave a $15.54 \pm$ $0.7 \%$ of initial burst release at $1 \mathrm{hr}$ and $97.39 \pm 0.37 \%$ at end of $24 \mathrm{hrs}$, tablet was intact and a gel layer remained at end of 24hrs. The comparative dissolution profile of F3 and F5 were shown in Fig. 5(B).From the results it can be concluded that the viscosity of HPMC has a little effect in the lag time values. However, the \% CPC released from floating tablets was not affected and may be due to the water soluble nature of CPC. An attempt was also made with $20 \%$ w/w LVCR 100 (F6) (data was not considered) a low viscosity grade polymer however; the tablets were dissolved within $30 \mathrm{~min}$.
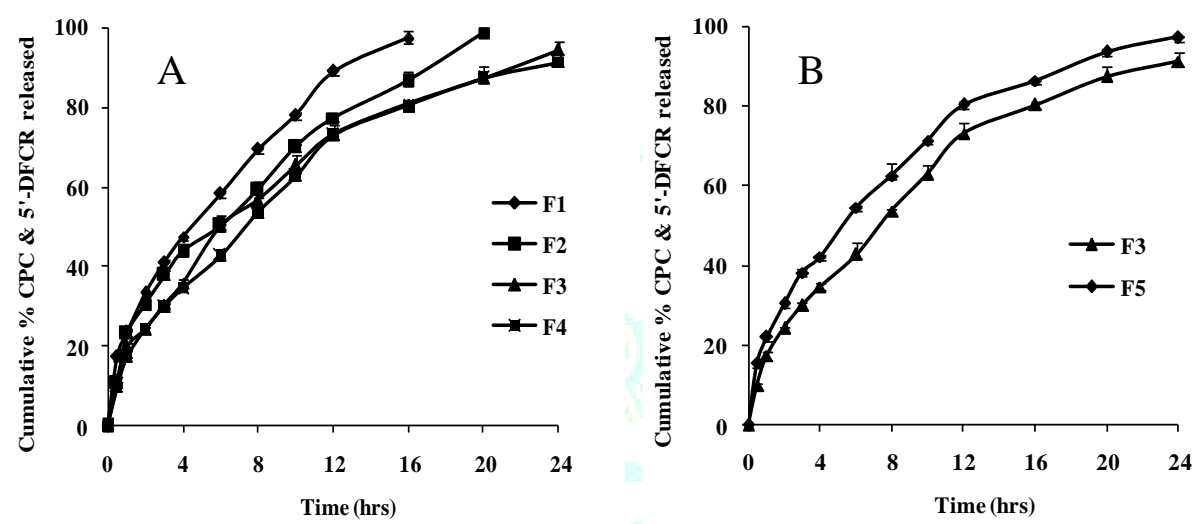

Fig.5: Comparative drug release profiles of - (A) HPMC K4M formulations at different concentrations with $\mathrm{NaHCO}_{3}$; (B) formulations with different viscosities of $\mathrm{HPMC}$ with $\mathrm{NaHCO}_{3}$

Even though a continuous and sustained release of CPC was observed with F3 over a period of $24 \mathrm{hrs}$, reproducibility of hardness is a problem when $\mathrm{NaHCO}_{3}$ was used as a gas generating agent. Hence, further trials were carried out by replacing $\mathrm{NaHCO}_{3}$ with $\mathrm{CaCO}_{3}$ at same percent levels in the formulations i.e. $20 \% \mathrm{w} / \mathrm{w}$. F7- F9 were compressed with $\mathrm{CaCO}_{3}$ as gas generating agent containing $20 \% \mathrm{w} / \mathrm{w}$, $15 \% \mathrm{w} / \mathrm{w}$ and $10 \% \mathrm{w} / \mathrm{w}$ of HPMC K4M levels in floating tablets. F7, F8, F9 gave an initial burst release of $10.56 \pm$ $0.44 \%, 19.39 \pm 0.57 \%$ and $23.0 \pm 3.73 \%$ respectively at end of $1 \mathrm{hr}$ and $80.06 \pm 0.53 \%, 82.68 \pm 0.34 \%$ and $97.12 \pm 1.26 \%$ respectively at $24 \mathrm{hrs}$ time interval.
Overall, the CPC release was found to be inversely related to the concentration of HPMC present in the matrix structure i.e. higher the concentration the slower is CPC release from tablets. This was further confirmed by the MDT values. Moreover the increase in HPMC concentration also affected the floating lag time values i.e. lower the HPMC concentration lower the lag time values. Comparative dissolution profiles for $\mathrm{F} 3$ (containing $\mathrm{NaHCO}_{3}$ ) and $\mathrm{F} 7$ were given in Fig. 6(A).The comparative dissolution profile of F7, F8 and F9 were shown Fig.6 (B).
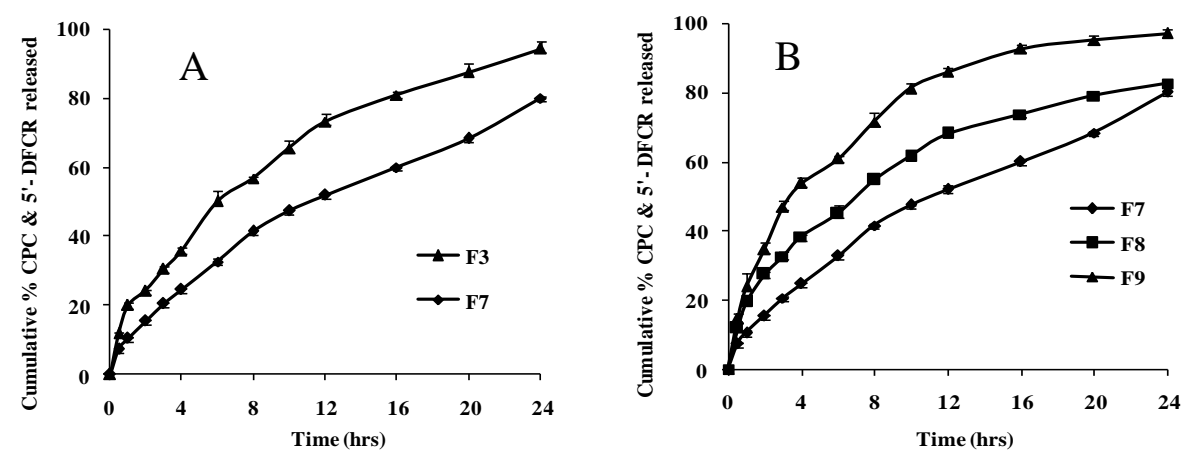

Figure 6: (A) -Comparative drug release profiles of formulations with $\mathrm{NaHCO}_{3}$ (F3) and $\mathrm{CaCO}_{3}$ (F7); (B) - Comparative drug release profiles of formulations with $\mathrm{HPMC} \mathrm{K4M} \mathrm{at} \mathrm{different} \mathrm{concentrations} \mathrm{with} \mathrm{CaCO}_{3}$ 


\section{Effect of Fillers on Lag Time Value:}

Effect Fillers such as PGS (F10), SDL with maize starch (F11) and DCP (F13) on CPC release was investigated. F10 gave a CPC release of $22.70 \pm 1.02 \%$ at $1 \mathrm{hr}$ and $99.54 \pm 0.55 \%$ at the end of $24 \mathrm{hrs}$. F10 though sustained the release of CPC from the floating tablets up to 24hrs; the lag time was significantly more when compared to F9 containing MCC as filler. The comparative dissolution profile for F9 and F10 is shown in Fig. 7. For F11 and F12 the reproducibility of hardness was a problem and tablets were not fulfilled the pharmacopoeial specifications.
Overall, the F9 containing $10 \% \mathrm{w} / \mathrm{w}$ HPMC $\mathrm{K} 4 \mathrm{M}$ as the release retardant, MCC as filler and $\mathrm{CaCO}_{3} 20 \% \mathrm{w} / \mathrm{w}$ as gas generating agent floated within $5 \pm 0.3 \mathrm{~min}$ and gave a good burst release of CPC (23.80 $\pm 3.73 \%)$ followed by controlled release of CPC (97.121 $\pm 1.26 \%)$ over a period of $24 \mathrm{hrs}$. The calculated MDT (min) value for formula F9 is $267 \mathrm{~min}$. F9 also fulfilled the regulatory requirements in terms of percent drug release (not less than $85 \%$ at the end of dissolution studies i.e. $24 \mathrm{hrs})^{18}$.

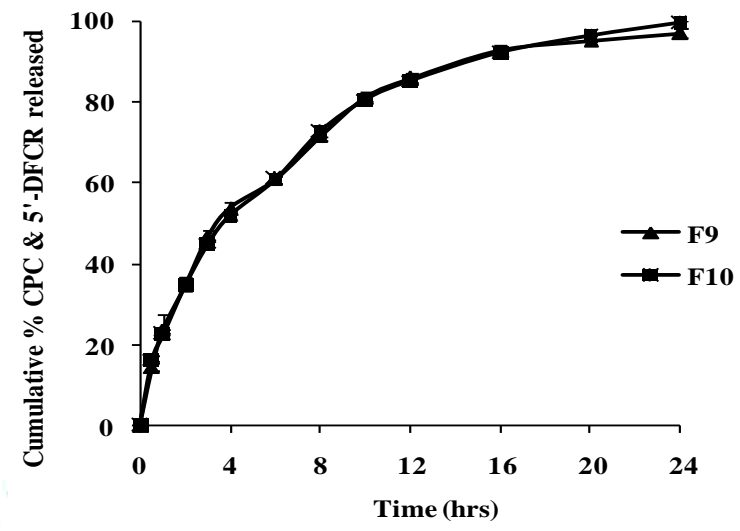

Figure 7: Comparative drug release profiles of formulations with MCC (F9) and PGS (F10)

\section{Drug Release Kinetics and mechanism:}

The results of kinetic models for CPC \& 5'-DFCR release from floating tablets were shown in Table II. The coefficient of correlation $\left(R^{2}\right)$ was used as an indicator of the best fitting for each of the models considered. The results reveal that all formulations best fit in the First order model. The mechanism of drug release from these tablets was found to be diffusion, as seen from high $R^{2}$ values of the Higuchi model. The data obtained were fitted in the Korsmeyer-Peppas model in order to find out the $n$ value. The release showed a high correlation with the Korsmeyer-Peppas model. The $n$ value ranged from 0.45 to 0.66 , which suggested that drug release from the mixture of polymers was non-Fickian diffusion controlled and was influenced by both swelling and erosion of floating tablets.

Table II: In vitro release kinetic parameters of CPC floating tablets

\begin{tabular}{|c|c|c|c|c|c|c|c|c|c|}
\hline \multirow{2}{*}{ Formulation } & \multicolumn{2}{|c|}{ Zero order } & \multicolumn{2}{|c|}{ First order } & \multicolumn{2}{|c|}{ Higuchi } & \multicolumn{2}{|c|}{ Peppas } & \multirow{2}{*}{$\begin{array}{c}\text { MDT } \\
\text { (min) }\end{array}$} \\
\hline & $\mathbf{R}^{2}$ & $K_{0}\left(h^{-1}\right)$ & $\mathbf{R}^{2}$ & $K_{1}\left(h^{-1}\right)$ & $\mathbf{R}^{2}$ & $K_{n}\left(h^{-1 / 2}\right)$ & $\mathbf{R}^{2}$ & $\mathbf{N}$ & \\
\hline F1 & 0.82 & 3.83 & 0.96 & 0.16 & 0.99 & 24.41 & 0.99 & 0.50 & 377 \\
\hline F2 & 0.92 & 4.52 & 0.86 & 0.16 & 0.99 & 22.22 & 0.99 & 0.45 & 511 \\
\hline F3 & 0.91 & 3.74 & 0.98 & 0.11 & 0.95 & 20.21 & 0.96 & 0.49 & 534 \\
\hline F4 & 0.92 & 3.73 & 0.98 & 0.10 & 0.99 & 20.74 & 0.99 & 0.53 & 571 \\
\hline F5 & 0.89 & 3.80 & 0.98 & 0.13 & 0.98 & 20.85 & 0.99 & 0.56 & 517 \\
\hline F6 & - & - & - & - & - & - & - & - & - \\
\hline F7 & 0.96 & 3.14 & 0.98 & 0.06 & 0.98 & 16.59 & 0.99 & 0.66 & 810 \\
\hline F8 & 0.87 & 3.19 & 0.98 & 0.07 & 0.98 & 17.70 & 0.99 & 0.48 & 581 \\
\hline F9 & 0.80 & 3.73 & 0.99 & 0.15 & 0.96 & 19.48 & 0.99 & 0.59 & 267 \\
\hline F10 & 0.82 & 3.81 & 0.94 & 0.19 & 0.97 & 21.51 & 0.99 & 0.60 & 250 \\
\hline
\end{tabular}




\section{CONCLUSION}

From the results obtained it can be concluded that, developing a once-daily oral proto-type gastro retentive dosage forms GRDFs of CPC based on the floating technology may increase the CPC pharmacotherapy as the CPC is released locally in the stomach leading to high drug concentrations at the gastric mucosa over a period of time in continuous manner thus reducing the frequency of administration. Overall, the floating tablet formulations may result in effective treatment of stomach cancer when compared to the existing immediate releasetablets.

\section{ACKNOWLEDGEMENTS}

The authors are thankful to the Divi's Laboratories for providing Capecitabine sample and Siddhartha Academy of General and Technical Education, Vijayawada, for providing necessary facilities to carry out this research work.

\section{Conflict of Interest: No conflict of intrest}

\section{REFERENCES}

1. Parkin M, Freddie B, Ferlay J, Pisani P. Global Cancer Statistics - 2002. CA Cancer Journal for Physicians. 2005; 55(2):74-108.

2. Kamangar F, Dores GM, Anderson WF. Patterns of Cancer Incidence, Mortality and Prevalence across Five Continents: Defining Priorities to Reduce Cancer Disparities in Different Geographic Regions of the World. Journal of clinical oncology. 2006; 24(14):2137-50.

3. Ohta Y, Sueki K, Kitta K, Takemoto K, Ishitsuka H, Yagi Y. Comparative Studies on the Immunosuppressive Effect among 5-deoxy-5-fluorouridine, ftorafur and 5-fluorouracil. Japanese Journal of Cancer Research. 1980; 71:190-196.

4. Ninomiya Y, Miwa M, Eda H, Sahara H, Fujimoto K, Ishida M, Umeda I, Yokose $\mathrm{K}$, Ishitsuka $\mathrm{H}$. Comparative Antitumor Activity and Intestinal Toxicity of 5-deoxy-5- fluorouridine and its Prodrug Trimethoxybenzoyl-5-deoxy-5-fluorocytidine. Japanese Journal of Cancer Research. 1990; 81:188-195.

5. Ishikawa T, Sekiguchi F, Fukase Y, Sawada N, Ishitsuka H. Positive Correlation between the Efficacy of Capecitabine and Doxifluridine and the Ratio of Thymidine Phosphorylase to Dihydropyrimidine Dehydrogenase Activities in Tumors in Human Cancer Xenografts. Cancer Research. 1998; 58:685690.
6. Ishitsuka H. Capecitabine: Preclinical Pharmacology Studies. Investigational New Drugs. 2000; 18(4):343-354.

7. Sawada N, Ishikawa T, Fukase Y, Nishida M, Yoshikubo H. Induction of Thymidine Phosphorylase Activity and Enhancement of Capecitabine by Taxol/Taxotere in Human Cancer Xenografts. Clinical Cancer Research. 1998; 4(4):10131019.

8. Fujimoto ouchi K, Sekiguchi F, Moriya Y, Mori K, Tanaka Y. Antitumor Activity of Transtuzumab in Combination with Chemotherapy in Human Gastric Cancer Xenograft Models. Cancer Chemotherapy Pharmacology. 2007; 59(6):795-805.

9. Reigner B, Blesch K, Weidekamm E. Cinical Pharmacokinetics of Capecitabine. Clinical Pharmacokinetics. 2001; 40(2):85104.

10. Miwa M, Ura M, Nishida M, Sawada N, Ishikawa T, Mori K, Shimma N, Umeda I, Ishitsuka H. Design of a Novel Oral Fluoropyrimidinecarbamate, Capecitabine Which Generates 5-Fluorouracil Selectively in Tumours by Enzymes Concentrated in Human Liver and Cancer Tissue. European Journal of Cancer. 1998; 34:1274-1281.

11. Quinney SK, Sanghani SP, Davis WI, Hurley TD, Sun Z, Murry DJ, Bosron WF. Hydrolysis of Capecitabine to 5'-deoxy-5fluorocytidinebyhuman Carboxylesterases and Inhibition by Loperamide. The Journal of Pharmacology and Experimental Therapeutics. 2005; 313(3):1011-1016.

12. The United States Pharmacopoeia. National formulary. Vol. 1. Asian edition. Rockville (MD): United State Pharmacopoeial Convention Inc; 2007. Capecetibine; P. 643-645.

13. Lachman L, Lieberman HA, Joseph LK. The theory and practice of industrial pharmacy. $3^{\text {rd }}$ ed. Mumbai: Varghese publishing house; 1987. P. 296-300.

14. Lapidus H, Lordi NG. Drug Release from Compressed Hydrophilic Matrices. Journal of Pharmaceutical Sciences. 1966; 55: 840-843.

15. Higuchi T. Mechanism of Sustained Action Medication, Theoretical Analysis of Rate of Solid Drugs Dispersed in Solid Matrices. Journal of Pharmaceutical Sciences. 1963; 52:11451148.

16. Korsmeyer RW, Gurny R, Doelker E, Buri P, Peppas NA. Mechanism of Solute Release from Hydrophilic Polymers. International Journal of Pharmaceutics. 1983; 15:25-35.

17. O'Neil, M.J., ed. The Merck Index: An Encyclopedia of Chemicals, Drugs, and Biologicals, $13^{\text {th }}$ ed. New jersey: Merck, 2001.

18. Food and Drug Administration, Centre for Drug Evaluation and Research. Guidance- Dissolution testing of Extended Release Solid Oral Dosage forms. 1997. 